\title{
Biologic Effects of Parenteral Bisulfite on Human Vascular Tissue
}

\author{
JEAN-CLAUDE LAVOIE AND PHILIPPE CHESSEX \\ Perinatal Service and Research Center. Department of Pediatrics, University of Montreal. \\ Montreal. Quebec. Canada
}

\begin{abstract}
Antioxidant properties of bisulfite are used to stabilize parenteral amino acid solutions. After reports of adverse reactions to dietary sulfites, we evaluated whether the infusion of bisulfite had biologic effects on human vascular tissue. Because an endothelial oxidative injury can affect mediators of vasoreactivity, vascular pressure and prostaglandin production were studied in an intact human vein model infused with clinically relevant amino acid solutions differing only by their metabisulfite content $(0$ versus $300 \mathrm{mg} / \mathrm{L})$. The amino acid solution containing bisulfite presented higher venous pressure $(p<0.01)$ and prostaglandin production (6-keto-prostaglandin $\mathrm{F}_{1 \alpha}, p<$ 0.01 ; and prostaglandin $\mathrm{E}_{2}, p<0.05$ ). A hydroxyl radicalgenerating system added to the solutions did not modify the pressure readings, but it resulted in an overall decrease in prostacyclin production $(p<0.05)$. Despite this known inhibitory effect on oxidative challenge on prostaglandin $\mathbf{I}_{2}$ production, prostaglandins remained higher in the presence of bisulfite. The results suggest that the effect of bisulfite takes place before prostaglandin $\mathrm{H}_{2}$ synthesis in the eicosanoid cascade, whereas the oxidative challenge affects specifically the synthesis of prostaglandin $I_{2}$, after prostaglandin $\mathrm{H}_{2}$, indicating that there is no interaction between bisulfite and the hydroxyl generating system. Bisulfite has local vascular effects on endothelial mediators, separate from its antioxidant properties. (Pediatr Res 33: 347-351, 1993)
\end{abstract}

\section{Abbreviations}

Blend $\mathrm{C}$, studied solution containing an amino acid formulation with bisulfite

$\mathrm{PGE}_{2}$, prostaglandin $\mathrm{E}_{2}$

$\mathrm{PGH}_{2}$, prostaglandin $\mathrm{H}_{2}$

$\mathrm{PGI}_{2}$, prostaglandin $\mathrm{I}_{2}$

TIV, studied solution containing the same amino acid formulation as Blend $\mathrm{C}$, without bisulfite

6-keto-PGF $\mathrm{PG}_{1 \alpha}$, 6-keto prostaglandin $\mathrm{F}_{1 \alpha}$, stable metabolite of $\mathrm{PGI}_{2}$

Sulfites are widely used in food processing and in the pharmaceutical industry; these additives have antimicrobial properties, prevent fermentation as well as food discoloration, and exert antioxidant properties (1). But sulfites produce adverse reactions $(1,2)$; anaphylaxis, bronchospasm, and urticaria occurring

Received August 27, 1992; accepted November 24, 1992

Correspondence and reprint requests: Philippe Chessex, M.D., Research Center. Hôpital Sainte-Justine, 3175 Chemin Côte Sainte-Catherine, Montreal (Quebec), Canada H3T $1 \mathrm{C} 5$.

Supported by the Medical Research Council of Canada (UI-0035), as well as by grants from Baxter Corporation and Clintec Nutrition, Canada Inc. of Mississauga Ontario, and Fondation Justine-Lacoste-Beaubien, Montreal, Quebec, Canada. after ingestion of metabisulfite could be IgE-mediated (3), as these clinical manifestations were present mainly in patients with a history of hypersensitivity. The exact mechanism of sulfite-induced reactions remains unclear (4) and is still under investigation (5).

Bisulfite, which is present in several parenterai amino acid solutions used in neonatology, pediatrics, and adult medicine, is added during the manufacturing process to ensure stability during and after sterilization. After enteral alimentation, the sulfite is transformed in the liver by sulfite oxidase to a sulfate, which forms strong complexes with calcium ion and is eliminated in the urine (6). However, during parenteral nutrition, the bisulfite could exert a vascular action close to the site of infusion, before its transformation by the liver enzyme. Because of the adverse reactions to bisulfites in foods, methods were developed to manufacture parenteral amino acid solutions without bisulfite. This presented us with the opportunity to address the biologic effects of bisulfite on human tissue.

Solutions of i.v. alimentation produce specific vascular responses at the site of infusion (7), stressing the importance of vasoactive endothelial mediators and their relation to i.v. therapies such as parenteral nutrition. The bisulfite used to stabilize parenteral amino acid solutions (8) was suspected to interfere with the vasoactive mediators. An array of vasoactive biochemical factors has been described $(9-15)$, several of these factors act at the site of endothelial production, such as the eicosanoids (10). Prostaglandins are mediators that could be affected by antioxidant properties of bisulfite, inasmuch as the synthesis of prostaglandins is inhibited by oxidants such as peroxides and oxygen radicals $(16-18)$.

The objective of this study was to determine whether bisulfite infused with amino acid solutions influenced the local prostaglandin production and the venous tone in a human vascular model designed to study the local effects of parenteral nutrition. Prostaglandins from the endothelial membrane $\left(\mathrm{PGI}_{2}\right)$ and the cytoplasm $\left(\mathrm{PGE}_{2}\right)$ were measured to determine more closely the site of action of bisulfite.

\section{MATERIALS AND METHODS}

Experimental Model. Umbilical cord specimens from term repeat cesarean sections after normal pregnancies were prepared as follows. A 10-cm segment of undamaged cord was sampled. The vein kept intact in the cord was nozzeled at each end with a luer tape fitting (Cole-Parmer Instrument Co., Chicago, IL) and maintained in a phosphate buffer (sodium phosphate, 0.01 $\mathrm{mol} / \mathrm{L}$; glucose, $0.011 \mathrm{~mol} / \mathrm{L} ; \mathrm{KCl}, 0.004 \mathrm{~mol} / \mathrm{L} ; \mathrm{NaCl}, 0.14$ $\mathrm{mol} / \mathrm{L} ; \mathrm{pH} 7.4)$ at $37^{\circ} \mathrm{C}$. Respecting the anatomical direction of flow, the vein was perfused with the oxygenated $\left(95 \% \mathrm{O}_{2}\right.$ and $5 \% \mathrm{CO}_{2}$ ) solutions using a peristaltic pump (Flo-Gard 6100, Travenol Canada Inc., Mississauga, Ontario, Canada).

Studied Solutions. The studied solutions $(\mathrm{pH} 7.4)$ had a fixed proportion (0.5:0.14:0.36) of nutritive medium M199 (Flow Laboratories Inc., Mississauga, Ontario, Canada) containing 50 


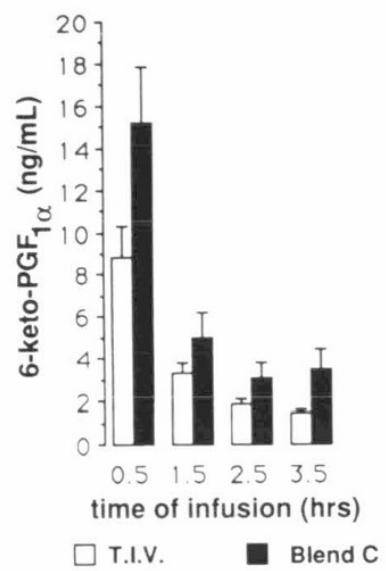

Fig. 1. Influence of bisulfite on prostacyclin production. Paired comparisons over time of 6-keto- $\mathrm{PGF}_{1 \alpha}$ production (stable metabolite of prostacyclin, $\mathrm{ng} / \mathrm{mL}=\mu \mathrm{g} / \mathrm{L}$ ) in six umbilical veins (mean $\pm \mathrm{SEM}$ ) perfused with either Blend $\mathrm{C}$ or TIV solution. The prostacyclin production was significantly greater $(p<0.01)$ during the Blend $\mathrm{C}$ infusion. There was a significant $(p<0.01)$ effect of time attributed to the model.

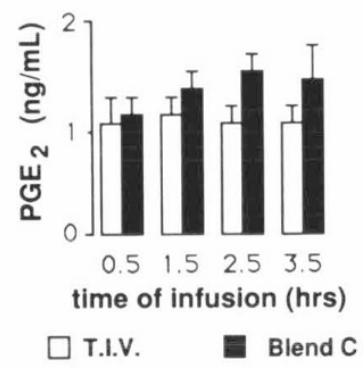

Fig. 2. Influence of bisulfite on $\mathrm{PGE}_{2}$ production. Paired comparisons over time of $\mathrm{PGE}_{2}$ production $(\mathrm{ng} / \mathrm{mL}=\mu \mathrm{g} / \mathrm{L})$ in six umbilical veins $($ mean $\pm \mathrm{SEM})$ perfused with either Blend $\mathrm{C}$ or TIV solution. The $\mathrm{PGE}_{2}$ production was significantly greater $(p<0.05)$ during the Blend $\mathrm{C}$ infusion and not affected by time.

$\mathrm{mmol} / \mathrm{L} \mathrm{NaHCO}$, amino acid solutions, and water plus electrolytes ( Na, $7.5 \mathrm{mmol}$; K, $6.0 \mathrm{mmol}$; $\mathrm{Cl}, 7.5 \mathrm{mmol}$; Ca, $5.0 \mathrm{mmol}$; $\mathrm{Mg}, 0.31 \mathrm{mmol} ; \mathrm{SO}_{4}, 0.31 \mathrm{mmol}$; and acetate, $13.7 \mathrm{mmol}$ ). The amino acid solutions differed only in their metabisulfite $\left(\mathrm{Na}_{2} \mathrm{~S}_{2} \mathrm{O}_{5}\right.$ ) content; Blend $\mathrm{C}$ (Travasol $10 \%$ Blend $\mathrm{C}$ amino acid solution; Clintec Nutrition, Mississauga, Ontario, Canada) contained $300 \mathrm{mg}$ metabisulfite/L and TIV (Travasol 10\% Blend C amino acid solution in Viaflex; Clintec Nutrition) was devoid of metabisulfite. It was verified that the amino acid profile of Blend C (19) was comparable to that of TIV. Furthermore, an oxidative challenge was added to the studied solutions, as a hydroxyl radical-generating system $\left(10 \mathrm{mmol} / \mathrm{L} \mathrm{H}_{2} \mathrm{O}_{2}+0.2 \mathrm{mmol} / \mathrm{L}\right.$ $\left.\mathrm{FeCl}_{2}\right)(20)$.

Experimental Design. Three series of measurements were undertaken comparing 1 ) Blend $\mathrm{C}$ versus TIV in six umbilical veins; 2) Blend $\mathrm{C}$ versus Blend $\mathrm{C}+$ hydroxyl radical in six additional veins; and 3) TIV versus TIV + hydroxyl radical in another six veins. Each solution of a pair was randomly assigned to two adjacent samples of the same length from a cord. In pilot studies, no relationships had been found between the site of umbilical cord section (proximity of the sample to the placenta) and the 6-keto-PGF - $_{1 \alpha}$ production or the pressure.

Within $0.5 \mathrm{~h}$ of birth, the vein was infused during $15 \mathrm{~min}$ with a flow rate set at $200 \mathrm{~mL} / \mathrm{h}$ to wash out residual blood; thereafter, the flow was maintained at a constant rate of $20 \mathrm{~mL} / \mathrm{h}$. At 20 $\mathrm{mL} / \mathrm{h}$, the dilution of prostaglandins was such that $\mathrm{PGE}_{2}$ and 6 keto-PGF ${ }_{1 \alpha}$ concentrations were above the threshold of detection and therefore directly measurable in the perfusate. Each aliquot of perfusate $(0.9 \mathrm{~mL})$ was sampled at the distal end of the vein at $0.5,1.5,2.5$, and $3.5 \mathrm{~h}$ of infusion, mixed with $0.1 \mathrm{~mL}$

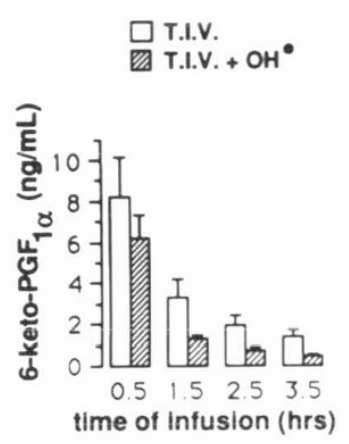

A
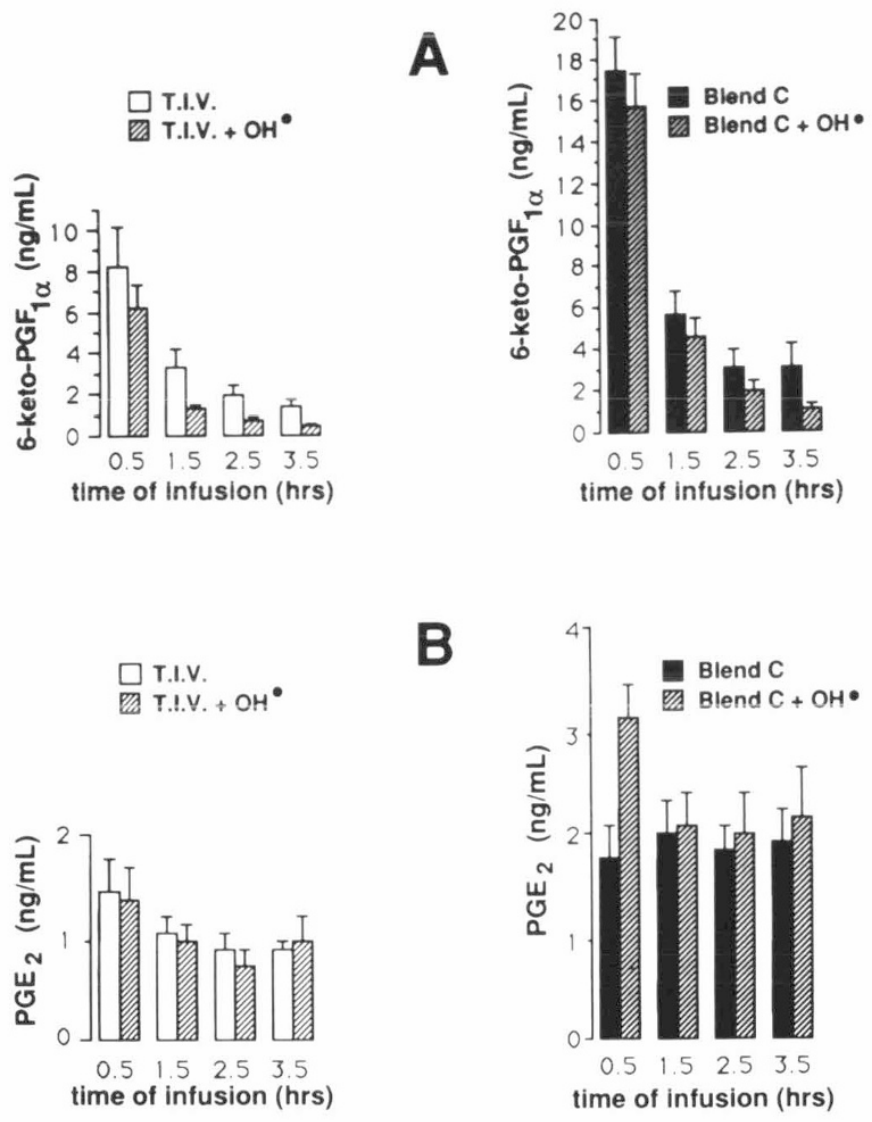

Fig. 3. Influence of an oxidative challenge on the prostaglandin responses induced by bisulfite. $A$, Paired comparisons over time of 6-keto$\mathrm{PGF}_{1 \alpha}$ production $(\mathrm{ng} / \mathrm{mL}=\mu \mathrm{g} / \mathrm{L})$ in two sets of six umbilical veins (mean $\pm \mathrm{SEM}$ ) between the studied solutions (Blend C, $n=6$; TIV, $n=$ 6 ) in the presence or absence of a hydroxyl radical-generating system. The 6-keto-PGF $F_{1 \alpha}$ production was significantly lower $(p<0.05)$ in the presence of the hydroxyl radical $\left(\mathrm{OH}^{\bullet}\right)$. B, paired comparisons over time of $\mathrm{PGE}_{2}$ production $(\mathrm{ng} / \mathrm{mL}=\mu \mathrm{g} / \mathrm{L})$ in two sets of six umbilical veins (mean $\pm \mathrm{SEM}$ ) between the studied solutions (Blend C, $n=6$; TIV, $n=$ 6 ) in the presence or absence of a hydroxyl radical-generating system. The $\mathrm{PGE}_{2}$ production was significantly greater $(p<0.01)$ during the Blend $\mathrm{C}+$ hydroxyl radical infusion. The comparison between the two groups of six veins revealed that the prostaglandin production was greater $(p<0.01)$ during the Blend $C$ hydroxyl radical infusions.

indomethacin $(200 \mu \mathrm{mol} / \mathrm{L}$ in M199), and immediately stored at $-70^{\circ} \mathrm{C}$ until prostaglandin determination. Pressure recordings were started $15 \mathrm{~min}$ after setting the flow rate at $20 \mathrm{~mL} / \mathrm{h}$ and subsequently each hour thereafter.

Analytical Procedures. Prostaglandins. $\mathrm{PGE}_{2}$ and 6-keto$\mathrm{PGF}_{1 \alpha}$ (the stable metabolite of $\mathrm{PGI}_{2}$ ) were measured directly on the sample by RIA using the antisera from Advanced Magnetics Inc. (Cambridge, MA). The technique used was proposed by the company. Briefly, after $2 \mathrm{~h}$ of incubation at $25^{\circ} \mathrm{C}$ with the antisera, the free ${ }^{3} \mathrm{H}$-tracer was separated by charcoal-dextran precipitation. An aliquot of the supernatant, reflecting the bound fraction, was counted. To verify whether the assay measured only prostaglandins, samples were measured before and after extraction on a reverse-phase Sep-Pack column (Waters Associates, Milford, MA) (21). For both prostaglandins, there was over $90 \%$ recovery.

The cross-reactivities at half of $\mathrm{Bo} / \mathrm{T}$ (bound in zero standard/ total count) for antisera against 6-keto-PGF ${ }_{1 \alpha}$ werc 6 -keto-PGE $=6.8 \%, \mathrm{PGF}_{2 \alpha}=2.2 \%$, and $\mathrm{PGE}_{2}=0.6 \%$; for antisera against $\mathrm{PGE}_{2}$ they were $\mathrm{PGE}_{1}=50 \%, \mathrm{PGF}_{2 \alpha}=1.3 \%$, and 6-keto-PGF $\mathrm{P}_{1 \alpha}$ $=0.1 \%$. The levels of detection within a $95 \%$ confidence limit were $0.20 \mathrm{ng} / \mathrm{mL}(\mu \mathrm{g} / \mathrm{L})$ for 6-keto-PGF ${ }_{1 \alpha}$ and $0.34 \mathrm{ng} / \mathrm{mL}(\mu \mathrm{g} /$ 
Table 1. Summary of statistical analyses for data in Figures 1, 2, and 3*

\begin{tabular}{|c|c|c|c|}
\hline Variables & $\begin{array}{l}\text { Degrees of } \\
\text { freedom }\end{array}$ & $\begin{array}{l}F \text { value for } \\
6 \text { keto-PGF } \\
1 \alpha\end{array}$ & $\begin{array}{c}F \text { value for } \\
\mathrm{PGE}_{2}\end{array}$ \\
\hline \multicolumn{4}{|l|}{ Figures 1 and 2} \\
\hline Intersubject & 5,42 & 1.03 & $5.11 \dagger$ \\
\hline Blend C vs TIV & 1,35 & $14.22 \dagger$ & $6.27 \ddagger$ \\
\hline Time & 3,35 & $37.63 \dagger$ & 0.90 \\
\hline Interaction & 3,35 & 2.52 & 1.01 \\
\hline \multicolumn{4}{|l|}{ Figure 3} \\
\hline Intersubject & 11,84 & 1.49 & $11.70 \dagger$ \\
\hline 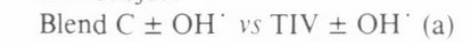 & 1,10 & $17.55 \dagger$ & $14.28 \dagger$ \\
\hline Blend $\mathrm{C}$ vs Blend $\mathrm{C}+\mathrm{OH}^{\circ}$ (b) & 1,70 & $4.61 \ddagger$ & $16.04 \dagger$ \\
\hline TIV vs TIV $+\mathrm{OH}^{-}$(c) & 1,70 & $4.81 \ddagger$ & 0.17 \\
\hline Time & 3,70 & $99.59 \dagger$ & $22.09+$ \\
\hline \multicolumn{4}{|l|}{ Interactions } \\
\hline Time (a) & 3,70 & $15.98^{\dagger}$ & 0.09 \\
\hline Time in Blend $\mathrm{C} \pm \mathrm{OH}^{\circ}$ & 3,70 & $97.65 \dagger$ & $3.64 \ddagger$ \\
\hline Time in TIV $\pm \mathrm{OH}^{-}$ & 3,70 & $17.92 \dagger$ & $4.91 \dagger$ \\
\hline Time (b) & 3,70 & 0.13 & $5.46 \dagger$ \\
\hline Time in Blend $\mathrm{C}$ & 3,70 & & 0.26 \\
\hline Time in Blend $\mathrm{C}+\mathrm{OH}^{\circ}$ & 3,70 & & $8.86^{\dagger}$ \\
\hline Time (c) & 3,70 & 0.20 & 0.12 \\
\hline
\end{tabular}

${ }^{*} \mathrm{OH}^{*}$, hydroxyl radical.

$\dagger p<0.01$.

$\ddagger p<0.05$.

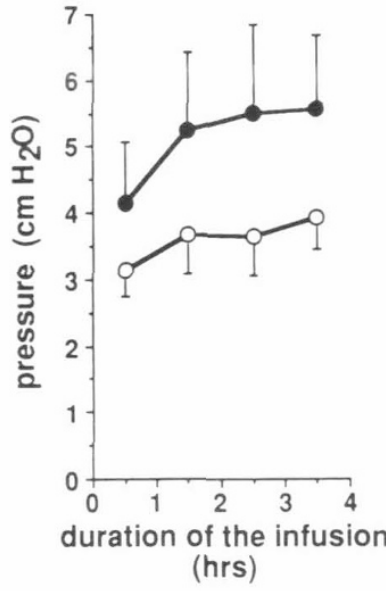

$\rightarrow$ T.I.V.

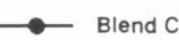

Fig. 4. Influence of bisulfite on venous pressure. Paired comparisons over time of venous pressure measurements in six umbilical veins (mean \pm SEM) perfused with either Blend $C$ or TIV solution. The pressure was higher $(p<0.01)$ during the Blend $\mathrm{C}$ infusion.

L) for $\mathrm{PGE}_{2}$. The intraassay coefficient of variation was $4 \%$, and the interassay variation was $15 \%$.

The pressure generated by the vessel was measured at the proximal end with a water column and changes from baseline were recorded.

Cellular viability. The endothelial cells were isolated according to the method of Jaffe et al. (22). The cells from $5 \mathrm{~cm}$ of the vein were isolated after incubation with $0.2 \%$ (wt/vol) collagenase (CLS, Worthington Biochemical Corporation. Freehold, NJ) for $15 \mathrm{~min}$ at $37^{\circ} \mathrm{C}$. The cellular viability was determined by counting on a hemocytometer, using the method of exclusion of trypan blue $(0.1 \%$ in cellular suspension).

Lipoprotein lipase. The activity was measured in situ. Two $\mu \mathrm{mol} / \mathrm{L}$ of the substrate glycerol tri $\left[1-{ }^{14} \mathrm{C}\right]$ oleate (Amersham. Oakville, Ontario, Canada) were directly incubated in the vein: $0.5 \mathrm{~mL}$ of substrate was incubated in $8 \mathrm{~cm}$ of vein for $90 \mathrm{~min}$. The enzyme was measured according to Nilson-Ehle and Schotz (23).

Statistical Analysis. The effects of time and treatments were
Table 2. Summary of statistical analyses for data in Figures 4 and $5^{*}$

\begin{tabular}{|c|c|c|}
\hline Variables & $\begin{array}{l}\text { Degrees of } \\
\text { freedom }\end{array}$ & $\begin{array}{c}F \text { value for } \\
\text { pressure }\end{array}$ \\
\hline \multicolumn{3}{|l|}{ Figure 4} \\
\hline Intersubject & 5.42 & $13.65+$ \\
\hline Blend $C$ vs TIV & 1,35 & $10.03+$ \\
\hline Time & 3.35 & 1.06 \\
\hline Interaction & 3,35 & 0.27 \\
\hline \multicolumn{3}{|l|}{ Figure 5} \\
\hline Intersubject & 11,84 & $18.18 \dagger$ \\
\hline Blend $\mathrm{C}^{\prime} \pm \mathrm{OH}^{\prime}$ vs $\mathrm{TIV} \pm \mathrm{OH}^{-}$(a) & 1,10 & 3.48 \\
\hline Blend $\mathrm{C}$ vs Blend $\mathrm{C}+\mathrm{OH}^{-}$(b) & 1,70 & 1.5 \\
\hline $\mathrm{TIV} v s \mathrm{TIV}+\mathrm{OH}^{\circ}$ (c) & 1.70 & 0.01 \\
\hline Time & 3,70 & $8.97 \dagger$ \\
\hline \multicolumn{3}{|l|}{ Interactions } \\
\hline Time (a) & 3.70 & 1.87 \\
\hline Time (b) & 3,70 & 0.53 \\
\hline Time (c) & 3,70 & 0.17 \\
\hline
\end{tabular}

* $\mathrm{OH}$, hydroxyl radical.

$\dagger p<0.01$.

separated by a factorial analysis of variance; all comparisons were paired and performed orthogonally. The data are presented as mean \pm SEM. The level of significance was set at $p<0.05$. A summary of statistical analyses is presented in Tables 1 and 2.

\section{RESULTS}

The functional integrity of the endothelial cells was tested at the time of preparation of the model by measuring the cellular viability (mean \pm SEM, $91 \pm 3 \%, n=6)$, and the activity of the lipoprotein lipase; that activity $(10.0,1.6$, and $2.3 \mathrm{pmol} / 90 \mathrm{~min})$ was in the same order of magnitude as levels found in human placenta on the fetal side (24).

The results presented in Figures 1 through 3 show separate effects of time and treatments; the statistical analysis is presented in Table 1. Although the duration of the infusion significantly affected the synthesis of $\mathrm{PGI}_{2}$, time did not interfere with the pressure readings (Fig. 4, Table 2 ).

The productions of 6-keto-PGF $\mathrm{PG}_{1 \alpha}$ (Fig. 1) and $\mathrm{PGE}_{2}$ (Fig. 2) were higher with Blend $\mathrm{C}$ (with bisulfite). To determine whether 

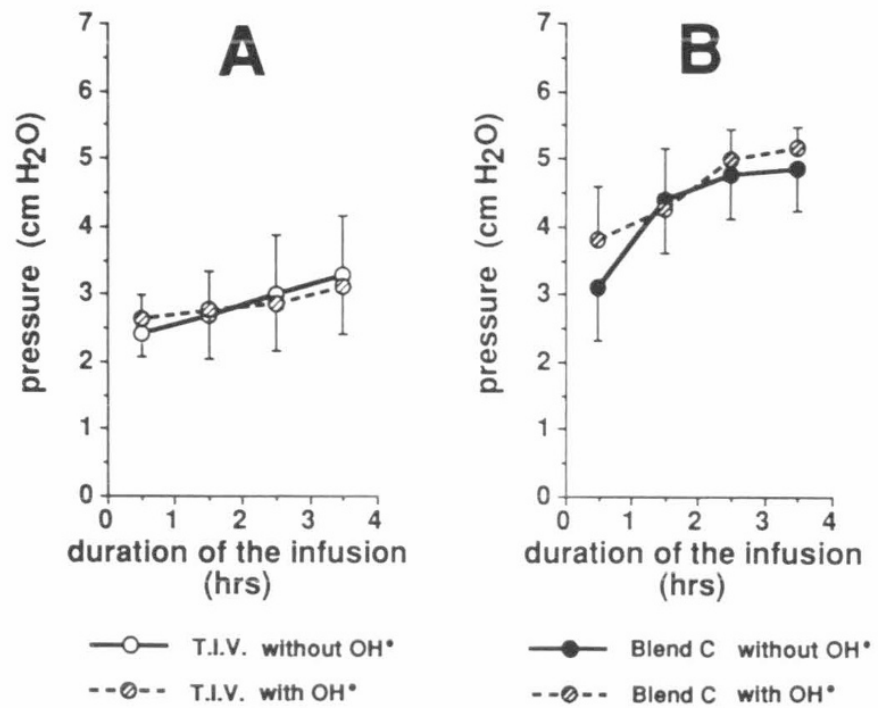

Fig. 5. Influence of an oxidative challenge on the venous pressure induced by amino acid solutions with or without bisulfite. Paired comparisons over time of venous pressure measurements (mean \pm SEM) between TIV with and without the hydroxyl radical $\left(\mathrm{OH}^{\bullet}\right)$ in six umbilical veins $(A)$ and between Blend $C$ with and without the hydroxyl radical in six additional umbilical veins $(B)$. The presence of the hydroxyl radical did not significantly interfere with the pressure.

this prostaglandin stimulation by bisulfite was related to its effect on oxidants present in the oxygenated medium, the studied solutions were additionally challenged with the hydroxyl radical (Fig. 3). In both solutions, this oxidative stress inhibited the 6keto-PGF $\mathrm{I}_{\alpha}$ production; however, the values remained higher with Blend $\mathrm{C}$. The significant increase in $\mathrm{PGE}_{2}$ due to the hydroxyl radical was observed only with Blend $C$; the statistical analysis of the interaction between treatment and time (Table 1) showed that the effect of the hydroxyl radical on $\mathrm{PGE}_{2}$ production in Blend $\mathrm{C}$ was affected by time, as well. The results from Figure $3 B$ suggest that the effect of the hydroxyl radical on this eicosanoid occurred early in the infusion. The venous tone was greater during the infusion of the bisulfite-containing solution (Fig. 4). In this model, we could find no correlation between changes in pressure and $\mathrm{PGI}_{2}$ or $\mathrm{PGE}_{2}$ production. Furthermore, the inhibition of prostacyclin by the hydroxyl radical was not reflected in the pressure readings (Fig. 5). These results document that bisulfite had biologic effects on prostaglandins as well as on vascular tone.

\section{DISCUSSION}

This study demonstrates that the bisulfite used in parenteral nutrition modifies local vasoreactivity. This finding is of importance because sulfites are widely used additives in drugs and in nutrition to prevent oxidative-induced degradation.

The similarity of values obtained in repeat experiments with TIV and Blend C (Figs. 1 and 2 versus Fig. 3) underlines the reproducibility of the data and therefore the reliability of the model. Although the physiologic flow rate in the human umbilical cord is about $7.3 \mathrm{~L} / \mathrm{h} / \mathrm{kg}(25)$, it was not practical to mimic this flow rate in the laboratory. The experimental flow was chosen to obtain a pressure reading and levels of prostaglandins directly measurable in the perfusate. The effect of time is to be considered separately from the effect of bisulfite, because it appears that the source of variation due to time is inherent in the model. Indeed, the overall decrease in 6-keto-PGF ${ }_{1 \alpha}$ over time was similar to the prostaglandin response found in the abdominal aorta of the rat. infused at a similar flow rate (26). The initially elevated prostacyclin production could be related to the manipulations required to prepare the vessel (26). However, this does not explain why $\mathrm{PGE}_{2}$ was not affected.
Because oxidants inhibit the synthesis of prostaglandins (1618 ), one could interpret the stimulatory effects of bisulfite on prostaglandins (Figs. 1 and 2) as a protection against oxidants present in the studied solutions. To verify this hypothesis, the solutions were challenged with a system known to generate oxygen-reactive substances (20), which are present after reperfusion with oxygenated solutions (16). The expected response to the oxidative challenge was a decrease in prostaglandin production (16-18) with both amino acid solutions (Fig. 3) because the antioxidant capacity of bisulfite in Blend $\mathrm{C}$ should be overloaded by the 40-times-higher molar concentration of peroxide used for this challenge. Despite the significant decrease in 6-keto-PGF ${ }_{1 a}$ induced by the addition of the hydroxyl radical to Blend $C$, the level of 6-keto-PGF ${ }_{1 \alpha}$ was still twice as high as that observed with TIV, which is devoid of bisulfite (Fig. 3). The statistical analysis demonstrates that for 6-keto-PGF $F_{1 \alpha}$, there is no interaction between bisulfite and this oxidative challenge. Therefore, the persistence of a stimulatory effect of bisulfite on prostaglandins despite an oxidative challenge (Fig. 3) underlines that bisulfite has biologic effects that are separate from its antioxidant properties.

This effect of bisulfite has to take place before $\mathrm{PGH}_{2}$ synthesis in the eicosanoid cascade because it affects $\mathrm{PGI}_{2}$ as well as $\mathrm{PGE}_{2}$. On the other hand, the free oxygen radical has an inhibitory effect on prostacyclin synthase (27) as supported by the results of Fig. 3A. This would explain why the hydroxyl radical-enriched system leads to an increase in $\mathrm{PGE}_{2}$ only when stimulated by bisulfite, as the availability of $\mathrm{PGH}_{2}$ is increased by both bisulfite and the oxidative challenge, the latter inhibiting the further conversion of $\mathrm{PGH}_{2}$ to $\mathrm{PGI}_{2}$.

Even though the endothelium, which produces the prostaglandins, represents an important body compartment, one should be cautious in extrapolating the vascular effects of bisulfite to other organs, tissues, or species. Clyman et al. (28) reported different effects of reactive oxygen metabolites on the pulmonary circulation in the lamb and the rabbit. Physiologic differences also exist between vessels of the same species (29). Furthermore, the changes in $\mathrm{PGI}_{2}$ and $\mathrm{PGE}_{2}$ did not account for the variations in vascular tone, which is not surprising, considering the many other endothelial mediators such as endothelium-derived relaxing factor (30) and endothelin (31).

In a variety of food products, bisulfite is used for the purpose of manufacturing stability, not for biologic or clinical reasons. We show here that parenteral bisulfite has biologic effects. Although the vasoreactivity induced by bisulfite was statistically documented, the clinical significance of these findings must be carefully evaluated. In view of the general willingness to eliminate sulfites from the diet, one should verify that the biologic effects outweigh the antioxidant properties before removing this additive or replacing it with another antioxidant.

Acknowledgment. The authors thank David Madsen, Ph.D., from Clintec Technologies in Deerfield, IL, for his helpful comments in reviewing this article.

\section{REFERENCES}

1. Yang WH, Purchase ECR 1985 Adverse reactions to sulfites. Can Med Assoc J 133:865-877

2. Wolf SI, Nicklas RA 1985 Sulfite sensitivity in a seven-year-old child. Ann Allergy 54:420-423

3. Prenner BM, Stevens JJ 1976 Anaphylaxis after ingestion of sodium bisulfite. Ann Allergy 37:180-182

4. Ito K, Kawanishi S 1991 Site-specific fragmentation and modification of albumin by sulfite in the presence of metal ions or peroxidase $/ \mathrm{H}_{2} \mathrm{O}_{2}$ : role of sulfate radical. Biochem Biophys Res Commun 176:1306-1312

5. Mansour E, Ahmed A, Cortes A, Caplan J, Burch RM, Abraham WM 1992 Mechanisms of metabisulfite-induced bronchoconstriction: cvidence for bradykinin $\mathrm{B}_{2}$-receptor stimulation. J Appl Physiol 72:1831-1837

6. Marangella M, Petrarulo M, Cosseddu D, Vitale C, Linari F 1991 Plasma profiles and removal rates of inorganic sulphate, and their influence on serum ionized calcium, in patients on maintenance haemodialysis. Clin Sci $80: 489-495$ 
7. Pineault M, Chessex P, Piedboeuf B, Bisaillon S 1989 Beneficial effect of coinfusing a lipid emulsion on venous patency. JPEN 13:637-640

8. Cole D 1986 Sulfites and parenteral nutrition. Can Med Assoc J 134:17-18

9. Samuelsson B, Dahléen SE, Lindgreen JA, Rouzer CA, Serhan CN 1987 Leukotrienes and lipoxins: structures, biosynthesis, and biological effects. Science 237:1171-1176

10. Mitchell JRA 1983 Clinical aspects of the arachidonic acid-thromboxane pathway. Br Med Bull 39:289-295

11. Fitzgerald DJ. Fragetta J, Fitzgerald GA 1988 Prostaglandin endoperoxides modulate the response to thromboxane synthase inhibition during coronary thrombosis. J Clin Invest 82:1708-1713

12. Gibb W, Lavoie JC 1990 Effects of glucocorticoids on prostaglandin formation by human amnion. Can J Physiol Pharmacol 68:671-676

13. Yanagisawa M, Kurihara H, Kimura S, Tomobe Y, Kobayashi M, Mitsui Y, Yasaki Y, Goto K, Masaki T 1988 A novel potent vasoconstrictor peptide produced by vascular endothelial cells. Nature 332:411-415

14. Rubanyi GM, Romero JC, Vanhoutte PW 1986 Flow-induced release of endothelium-derived relaxing factor. Am J Physiol 250:H1145-H1449

15. Gryglewski RJ, Trybolec M, Radziszewski W. Swierkosz T, Dudek R. Zembowicz A 1988 Endothelium-derived relaxing factor (EDRF) from cultured and fresh endothelial cells. Biomed Biochim Acta 47:S61-S66

16. Tate RM. Morris HG, Schroeder WR, Repine JE 1984 Oxygen metabolites stimulate thromboxane production and vasoconstriction in isolated salineperfused rabbit lungs. J Clin Invest 74:608-613

17. Markey CM. Alward A, Weller PE, Marnett LJ 1987 Quantitative studies of hydroperoxide reduction by prostaglandin $\mathrm{H}$ synthase. J Biol Chem 262:6266-6279

18. Egan RW, Gale PH, Kuehl Jr FA 1979 Reduction of hydroperoxides in the prostaglandin biosynthetic pathway by a microsomal peroxidase. J Biol Chem 254:3295-3302
19. Pineault M. Chessex P. Lepage D. Dallaire L. Brisson G 1986 Total parenteral nutrition in very low birthweight infants with Travanol $10 \%$ Blend C. JPEN 10:296-299

20. Pitkänen O. Hallman M. Anderson S 1991 Generation of free radicals in lipid emulsion used in parenteral nutrition. Pediatr Res 29:56-59

21. Powell WS 1982 Rapid extraction of arachidonic acid metabolites from biological samples using octadecylsilyl silica. Methods Enzymol 86:467-477

22. Jaffe EA, Nachman RL, Becker CG. Minick CR 1973 Culture of human endothelial cells derived from umbilical veins. Identification by morphologic and immunologic criteria. J Clin Invest 52:2745-2756

23. Nilson-Ehle P. Schotz MC 1976 A stable. radioactive substrate emulsion for assay of lipoprotein lipase. J Lipid Res 17:536-541

24. Mallov S, Alousi AA 1965 Lipoprotein lipase activity of rat and human placenta. Proc Soc Exp Biol Med 119:301-316

25. Griffin D. Cohen-Overbeek T. Campbell S 1983 Fetal and utero-placement blood flow. Clin Obstet Gynecol 10:565-602

26. Quadt JFA. Voss R. ten Hoor F 1982 Prostacyclin production of the isolated pulsatingly perfused rat aorta. J Pharmacol Methods 7:263-270

27. Ham EA. Egan RW. Soderman DD, Gale PH. Kuehl FA 1979 Peroxidasedependent deactivation of prostacyclin synthase. J Biol Chem 254:21912194

28. Clyman RI. Sauagstad OD, Mauray F 1989 Reactive oxygen metabolites relax the lamb ductus arteriosus by stimulating prostaglandin production. Circ Res 64:1-8

29. Charo IF, Shak S, Karasek MA. Davison PM, Goldstein IN 1984 Prostaglandin $\mathrm{I}_{2}$ is not a major metabolite of arachidonic acid in cultured endothelial cells from human foreskin microvessels. J Clin Invest 74:914-919

30. Newby AC. Henderson AH 1990 Stimulus-secretion coupling in vascular endotheliai ceils. Annu Rev Physioi 52:6́ó i-674

31. Simonson MS, Dunn MJ 1990 Endothelin: pathways of transmembrane signaling. Hypertension 15(suppl 1):I5-I12 